\title{
Automation and heat transfer characterization of immersion mode spectroscopy for analysis of ice nucleating particles
}

\author{
Charlotte M. Beall $^{1}$, M. Dale Stokes ${ }^{1}$, Thomas C. Hill ${ }^{2}$, Paul J. DeMott ${ }^{2}$, Jesse T. DeWald ${ }^{3}$, and Kimberly A. Prather ${ }^{1,4}$ \\ ${ }^{1}$ Scripps Institution of Oceanography, University of California San Diego, La Jolla, CA 92037, USA \\ ${ }^{2}$ Department of Atmospheric Science, Colorado State University, Fort Collins, CO 80523, USA \\ ${ }^{3}$ Jacobs School of Engineering, University of California San Diego, La Jolla, CA 92093, USA \\ ${ }^{4}$ Department of Chemistry, University of California San Diego, La Jolla, CA 92093, USA
}

Correspondence to: Charlotte M. Beall (cbeall@ucsd.edu)

Received: 20 December 2016 - Discussion started: 9 February 2017

Revised: 31 May 2017 - Accepted: 1 June 2017 - Published: 21 July 2017

\begin{abstract}
Ice nucleating particles (INPs) influence cloud properties and can affect the overall precipitation efficiency. Developing a parameterization of INPs in global climate models has proven challenging. More INP measurements including studies of their spatial distribution, sources and sinks, and fundamental freezing mechanisms - must be conducted in order to further improve INP parameterizations. In this paper, an immersion mode INP measurement technique is modified and automated using a software-controlled, realtime image stream designed to leverage optical changes of water droplets to detect freezing events. For the first time, heat transfer properties of the INP measurement technique are characterized using a finite-element-analysis-based heat transfer simulation to improve accuracy of INP freezing temperature measurement. The heat transfer simulation is proposed as a tool that could be used to explain the sources of bias in temperature measurements in INP measurement techniques and ultimately explain the observed discrepancies in measured INP freezing temperatures between different instruments. The simulation results show that a difference of $+8.4^{\circ} \mathrm{C}$ between the well base temperature and the headspace gas results in an up to $0.6^{\circ} \mathrm{C}$ stratification of the aliquot, whereas a difference of $+4.2{ }^{\circ} \mathrm{C}$ or less results in a thermally homogenous water volume within the error of the thermal probe, $\pm 0.2^{\circ} \mathrm{C}$. The results also show that there is a strong temperature gradient in the immediate vicinity of the aliquot, such that without careful placement of temperature probes, or characterization of heat transfer properties of the water and cooling environment, INP measurements can be biased toward colder temperatures. Based on a modified
\end{abstract}

immersion mode technique, the Automated Ice Spectrometer (AIS), measurements of the standard test dust illite NX are reported and compared against six other immersion mode droplet assay techniques featured in Hiranuma et al. (2015) that used wet suspensions. AIS measurements of illite NX INP freezing temperatures compare reasonably with others, falling within the $5^{\circ} \mathrm{C}$ spread in reported spectra. The AIS as well as its characterization of heat transfer properties allows higher confidence in accuracy of freezing temperature measurement, allows higher throughput of sample analysis, and enables disentanglement of the effects of heat transfer rates on sample volumes from time dependence of ice nucleation.

\section{Introduction}

\subsection{Background}

Ice nucleating particles (INPs) induce freezing of cloud droplets at temperatures above their homogeneous freezing point $\left(\sim-38^{\circ} \mathrm{C}\right)$ and at a relative humidity $(\mathrm{RH})$ below the homogeneous freezing $\mathrm{RH}$ of aqueous solution droplets at lower temperatures, influencing cold cloud lifetime, phase, and their optical and microphysical properties. INPs are comprised of a diverse population of particles, some species of which have complex sources and sinks; developing a parameterization of INPs in global climate models (GCMs) that results in a credible representation of global cloud coverage and the radiative balance remains a challenge (DeMott et al., 2010; Seinfeld et al., 2016; Burrows et al., 2013). 
In situ observations to close critical knowledge gaps such as the vertical distribution of INPs in the air column, the complex sources and sinks of biological INPs, and INP influence on cloud microphysics are identified as a high priority for the improvement of INP representation in GCMs (Seinfeld et al., 2016; Burrows et al., 2013). One of the largest biases in shortwave reflectivity exists over the Southern Ocean, and this bias may be influenced by poor representation of INPs over primarily oceanic regions (Trenberth and Fasullo, 2010; DeMott et al., 2010). Measurements of INP number concentrations, particularly in remote ocean regions, are needed to help develop parameterizations of ice nucleation for use in cloud-resolving models and GCMs. To further improve the parameterization of INPs, both field and laboratory measurements are needed to identify drivers of ice nucleation in clouds. Accurately defining the activation temperature of INPs is critical to understanding the influence of INPs on clouds and improving representation of INPs in GCMs because INP freezing temperatures influence cloud phase and lifetime in mixed-phase clouds, or the supersaturation or temperature conditions in which ice clouds can form (DeMott et al., 2003, Cziczo et al., 2013). INP concentrations applied in cloud and climate models must be accurate to within a factor of 10 to avoid biases that lead to significant differences in cloud radiative and microphysical properties (Phillips et al., 2003).

Several instruments and techniques exist, utilizing both online (real time) and offline (processed post-collection) approaches, for the measurement of INP number concentration and activation temperature across the range of ice nucleation mechanisms. Ice nucleation mechanisms include deposition nucleation, immersion, contact, and condensation freezing. However, some simulations find immersion freezing is the dominant ice nucleation mechanism globally from 1000 to $200 \mathrm{hPa}$ (Hoose et al., 2010); hence, most INP measurement techniques target immersion mode freezing. In Hiranuma et al. (2015), 17 online and offline immersion mode instruments were compared using illite NX as the dust standard. The major differences between the 17 instruments studied are described in detail therein; however in brief, all of the instruments fall into one of two categories: droplet assay techniques, in which INPs are immersed in water and distributed among an array of pico- to microliter scale droplets on a substrate and then cooled until frozen, or chamber techniques, in which droplets are passed through a temperature- and humidity-controlled chamber, where the freezing of droplets and their associated size change is detected with optical particle counters. Each of these techniques poses significant INP measurement challenges due to the rarity of INPs, which represent 1 in $10^{6}$ or fewer of total aerosol particles (Rogers et al., 1998), and mitigation requires large air sample volumes, which both limits the temporal sampling resolution and increases the chance of contamination, which can overwhelm subtle INP signals in the data. Making INP freezing temperature measurements can also present challenges, because sample droplets or crystals cannot be directly probed with thermal sensors throughout the cooling process without altering the fundamental shape or content of the droplet, and most thermal probes are not small enough to access nano- to microliter-sized droplets.

In this paper, an offline freezing assay technique for measurement of immersion mode INPs (Hill et al., 2014; Hiranuma et al., 2015) is automated using a softwarecontrolled, real-time image stream designed to leverage optical changes of water volume arrays to detect freezing events. The offline freezing assay is an immersion mode technique that is similar to the immersion mode droplet assay, with a difference in the type of substrate used. In both techniques, multiple water volumes are supported on a substrate which is cooled until the water volumes are frozen, and concentrations of INPs as a function of freezing temperature are calculated from fractions of unfrozen droplets per temperature (see Sect. 2.1). In droplet assays, water volumes are distributed on a cold stage as droplets during measurements. However, in the freezing assay, small aliquots of water, typically around $50 \mu \mathrm{L}$ each, are distributed in $1.2 \mathrm{~mL}$ wells within disposable polypropylene trays. The trays are mounted in aluminum blocks that are cooled during measurements (see Sect. 2.2). Albeit with significant loss of time resolution, droplet or freezing assays provide an offline alternative for INP measurement with fewer aerosol size limitations than online chamber techniques. For regular sampling on any surface site, INP samples may be collected on openface filters, which reduce sample inlet particle size biases and particle losses.

There are 10 current instruments for measuring immersion mode INP concentrations using picoliter to nanoliter droplet or liquid volume arrays on or within cooled surfaces: the Leeds Nucleation by Immersed Particles Instrument (NIPI) (Whale et al., 2015), the Bielefeld Ice Nucleation ARraY (BINARY) (Budke and Koop, 2015), the North Carolina State Cold Stage (NC State-CS) (Wright et al., 2013), the University of Colorado Raman Microscope Cold Stage (CU-RMCS) (Baustian et al., 2010; Wise et al., 2010), the Frankfurt Ice Nuclei Deposition FreezinG Experiment (FRIDGE) (Klein et al., 2010), the Colorado State University Ice Spectrometer (CSU-IS) (Hiranuma et al., 2015, SI), the LED-based Ice Nucleation Detection Apparatus (LINDA) (Stopelli et al., 2014), the Cryogenic Refrigerator Applied to Freezing Test (CRAFT) (Tobo, 2016), WISDOM (WeIzmann Supercooled Droplets Observation on Microarray) (Y. Rudich, personal communication, 2016), and the MicroOrifice Uniform Deposit Impactor-Droplet Freezing Technique (MOUDI-DFT) (Mason et al., 2015). Differences between the techniques include a variety of strategies to minimize the Wegener-Bergeron-Findeisen process, in which frozen droplets near liquid droplets take up water vapor as the liquid droplets shrink, the degree to which RH or evaporation is controlled, number and size of droplets (or samples) accommodated, measurable freezing temperature range, and how 
freezing events are detected. Almost all of the 10 techniques, with the exception of the CSU-IS, use a camera to image the droplets. The NIPI, FRIDGE, and NC-State CS save images at a frequency on the order of 1 image $^{-1}$ and postprocess a stream of images of the droplets with varying levels of automation in the determination of freezing events. BINARY and LINDA report the use of an algorithm similar to the one described here (see Sect. 2.2) in which changes in the 8 bit mean grey value of a monochrome image and the intensity of LED light transmitted, respectively, are used to detect the droplet's phase change. Additionally, the heat transfer properties of the new SIO-AIS (Scripps Institution of Oceanography-Automated ice Spectrometer) instrument are also characterized through a finite-element-analysis heat transfer simulation to evaluate the homogeneity of INP sample temperatures and identify optimal locations for the thermal probes. Finally, the standard test dust used in Hiranuma et al. (2015) was tested using the instrument and was compared against the six other droplet array immersion mode INP measurement techniques that reported wet-suspension measurements of illite NX.

\section{Automation of immersion mode ice spectroscopy}

\subsection{Theory of operation}

Immersion mode ice spectroscopy measures INP concentrations at specific temperatures of a liquid sample. INP measurements of air samples are made by collecting particles on a filter (or via impinging particles into liquid), immersing the filter in ultrapure water, and shaking particles off of the filter by hand or via an automated rotator (DeMott et al., 2016). The liquid sample is then distributed in microliter aliquots into a clean 96-well disposable polypropylene sample tray. An equal number and volume of aliquots of ultrapure water accompany each sample in the disposable tray as a control for contamination from the loading and/or ultrapure water. The sample trays are then inserted into an aluminum block that is cooled until the samples are frozen. The homogenous freezing point of water is $-38^{\circ} \mathrm{C}$, but either the 96 -well sample tray surface or impurities present in the water induce freezing at higher temperatures, typically starting at -25 to $-27^{\circ} \mathrm{C}$, which limits the lower temperatures for which INP number concentrations may be assessed. Cumulative INP number concentrations per temperature per volume are calculated using the fraction of unfrozen wells $f$ per given temperature interval:

$\mathrm{INP}=\frac{\ln (f)}{V}$,

where $V$ is the volume of the sample in each well (Vali, 1971). The fraction of unfrozen wells $f$ is adjusted for contamination by subtracting the number of frozen ultrapurewater wells per temperature interval from both the total num-

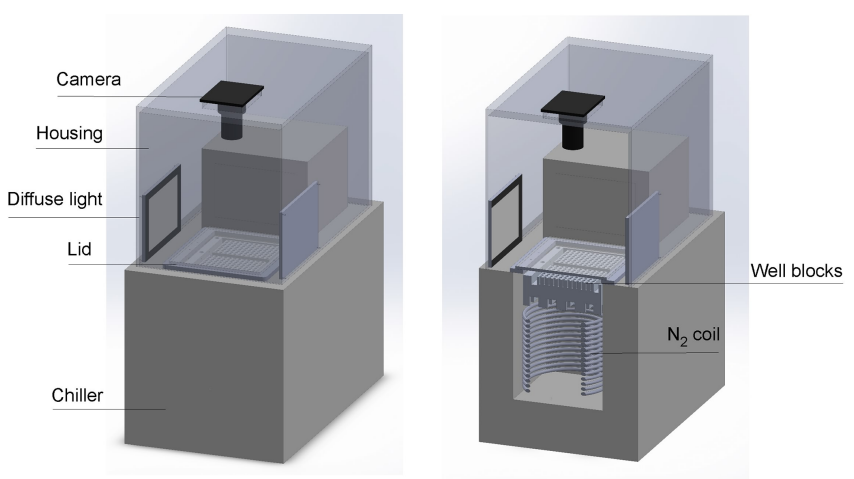

Figure 1. Schematic of Automated Ice Spectrometer (AIS) showing primary components as indicated by labels. Shown on the left is a camera, insulated housing for the camera and lights, LED diffuse lighting, a lid placed over the well blocks, and the chiller unit. Lid refers to the optically clear plexiglass cover, beneath which cold nitrogen gas is injected. Cutaway shows copper coil submerged in coolant that provides pre-chilled nitrogen gas to the space beneath plexiglass lid.

ber of unfrozen wells and the total number of wells of the sample.

\subsection{Physical design of the ice spectrometer}

In previous ice spectrometer INP studies, observation of each well-freezing event was conducted manually by an operator, which limited the number of samples and wells per sample that could be processed and required a cooling rate slow enough to accurately observe and manually record each freezing event. In order to increase sample throughput and improve accuracy of INP freezing temperature measurement, the immersion mode ice spectrometer (Hill et al., 2014; Hiranuma et al., 2015) was redesigned to increase sample cooling rates (see Figs. 1 and 2) and automated using a software-controlled camera that monitors changes in optical properties of water droplets during freezing. In this paper, the new instrument's maximum average cooling rate of $-0.87^{\circ} \mathrm{C} \mathrm{min}^{-1}$, as measured in the coolant bath from room temperature to $-33^{\circ} \mathrm{C}$, was used for all measurements and simulations. For the same temperature range, the average cooling rate as measured at the base of the well is the same. We do not investigate the role of cooling rate on freezing, known to influence freezing activation spectra to a much smaller extent than temperature alone (Vali, 2014).

In the new instrument, the Automated Ice Spectrometer (AIS), two aluminum well blocks are fixed inside the coolant bath cavity of a Fisher ${ }^{\mathrm{TM}}$ Isotemp ${ }^{\mathrm{TM}}$ refrigerated bath circulator and fitted with a sealed splash guard to prevent contamination of the well region by contact with the coolant. Each of the two aluminum blocks has a machined indentation cavity in which the 96-well disposable sample tray is tightly fitted. A plexiglass lid caps the well region to insu- 

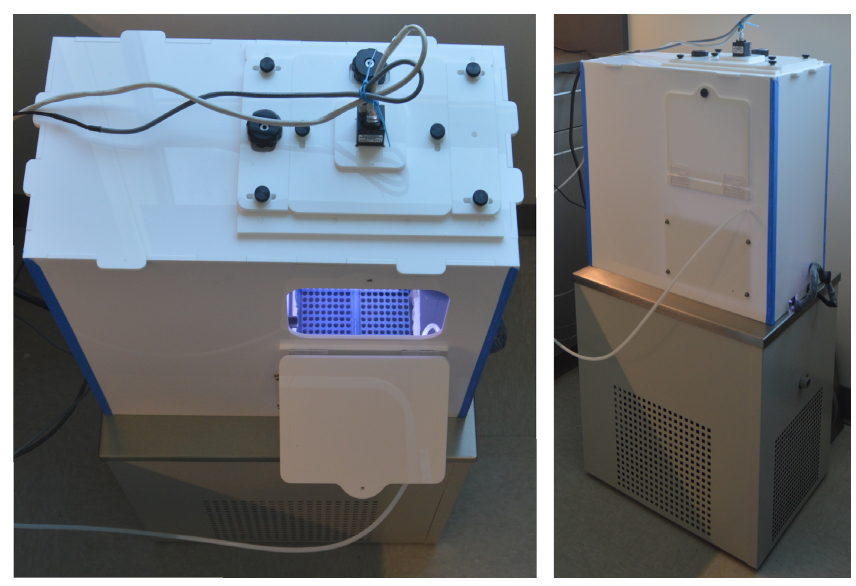

Figure 2. Photo of current Automated Ice Spectrometer system. Housing is manufactured from white cast acrylic. (a) Top-side view indicating camera and its adjustable cradle and access door open, showing cooled well plate within. (b) Oblique front view showing AIS housing sitting atop commercial chiller unit (Fisher Scientific Isotemp ${ }^{\circledR}$ circulator). Tubing shown is the nitrogen gas input line.

late and isolate the air above the wells from room temperature air. A $1.8 \mathrm{~mm}$ long, $0.64 \mathrm{~cm}$ diameter coiled copper tube, connected to an external dry-nitrogen supply, lies in the coolant bath beneath the well block in order to cool nitrogen gas that is pumped over the well region at $0.25 \mathrm{~L} \mathrm{~min}^{-1}$. The cold nitrogen gas purges room temperature air away from the well region to decrease stratification of temperature within the sample volumes. A flow rate of $0.25 \mathrm{~L} \mathrm{~min}^{-1}$ was chosen because it was found empirically to most effectively cool the air above the well region. The nitrogen gas enters the well region significantly warmer than the chilled bath temperature (about $+11{ }^{\circ} \mathrm{C}$; see Fig. 3 ) because the gas flows through approximately $15 \mathrm{~cm}$ of rubber tubing exposed to the ambient room temperature before being injected beneath the plexiglass cover, and the headspace gas is not perfectly isolated from room air heat. At flow rates less than $0.25 \mathrm{~L} \mathrm{~min}^{-1}$, room temperature air leaks into the well region, but at significantly higher flow rates the fast-flowing nitrogen gas lifts the acrylic plate, causing additional leakage.

A 0.5-megapixel monochrome camera (Point Grey Blackfly $0.5 \mathrm{MP}$ Mono GigE POE) is used to image the wells throughout the cooling process. As depicted in Fig. 4, the camera is controlled with custom National Instruments LabVIEW software, which allows the user to adjust imaging parameters including brightness, exposure, gain, and rotation via a graphical user interface control panel shown in Fig. 5. The refrigerated bath circulator is also controlled by the software and allows the user either to ramp the temperature of the coolant from room temperature to the input target temperature at a constant rate or to "stair-step" the coolant bath temperature at adjustable, incremented time and temperature steps (with the tolerance of the bath circulator thermostat and the starting and stopping temperature as additional input options).

As shown in Figs. 1 and 2, the camera is fixed above the well region at the top of a plastic housing fabricated from white cast acrylic sheet $(0.64 \mathrm{~cm}$ thick). An adjustable cradle holds the camera and allows aligning of the camera lens (2.8$12 \mathrm{~mm}$ Focal Length, Varifocal Video Lens, Edmund Optics) over the center of the well block. Also fixed within the white housing are two white LED backlights (Edmund Optics), one on either side of the well region, which together provide a stable lighting environment for imaging of the wells and the liquid samples. Once the camera is aligned using the adjustable cradle, the video image is live-streamed via the control software so that two $8 \times 12$ grids of $15 \times 15$ pixel squares are aligned over all 192 wells. Each $15 \times 15$ pixel box corresponds to an individual sample well, and the mean intensity of light reflected from each well is recorded.

When droplets freeze, the intensity of the light reflected back to the camera decreases due to the dark background of the inner well block. As in the flowchart depicted in Fig. 4, at each new time step $t_{i}$, if the difference between the mean intensity $I$ of the well at $t_{i}$ and the mean intensity of the well at $t_{i-1}$ is greater than the set pixel change threshold $\eta$ such that $\left|I\left(t_{i}\right)-I\left(t_{i-1}\right)\right|>\eta$, a freezing event is detected, and time, freezing temperature, and location of the well are recorded. The exposure, gain, and pixel change threshold $\eta$ can be adjusted in the control panel to increase the signalto-noise ratio by emphasizing the decrease in mean intensity due to freezing and minimizing the background variation in mean intensity due any oscillation of the chiller unit when the coolant circulator is running. Temperature measurements are made with a thermistor imbedded at the base of a well in the sample tray after threading the sensor leads through a small hole drilled in the aluminum block.

\section{Simulation of heat transfer for immersion mode ice spectroscopy}

\subsection{Model design}

In order to accurately measure the freezing temperature of INPs in immersion mode spectroscopy, the temperature of each well must be quantified, and the temperature of the sample throughout the volume itself must be homogenous (unstratified). Placing thermistors directly in the sample volume would be ineffective for several reasons, including that (1) the probe itself disrupts the structure of the surface of the droplet and could provide a surface for nucleation, (2) heat conducts through the probe into the sample volume, and (3) probes can introduce contamination. Also, if a probe is placed in a sacrificial sample well, once the well freezes, latent heat is released, and because the thermal properties of ice are different from those of water, the temperature of the frozen well may not be representative of the supercooled liq- 


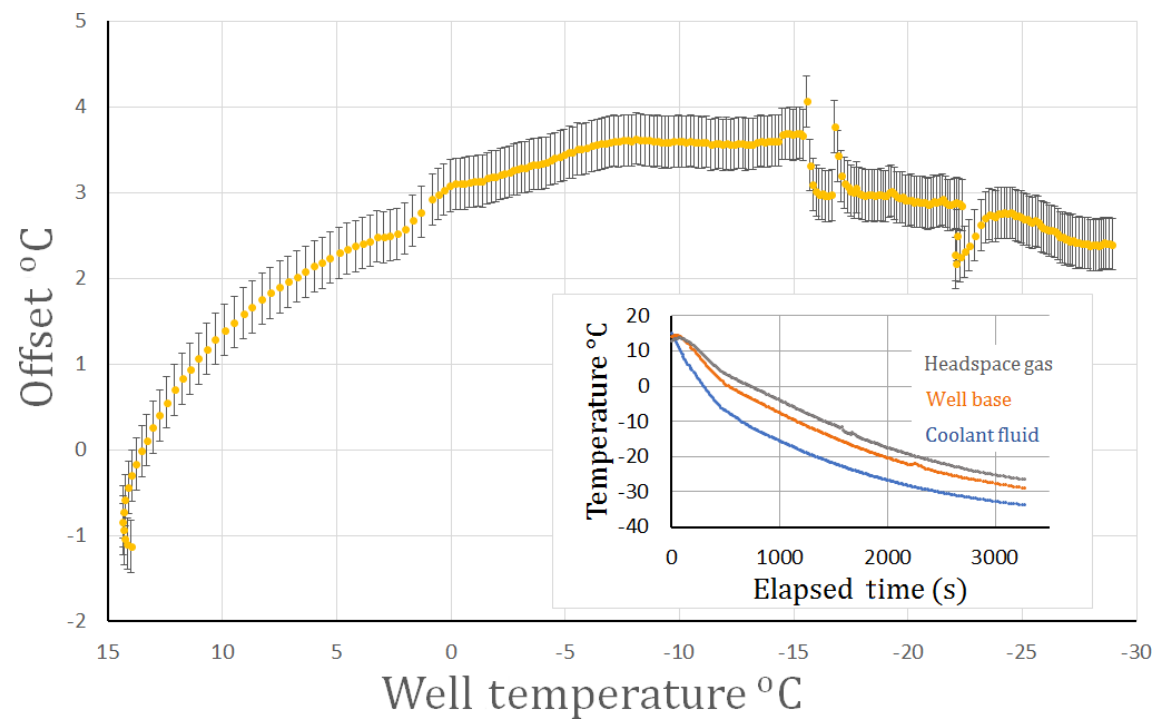

Figure 3. Graph of well temperature vs. temperature offset measured between the base of the well and the air above the well as measured with a thermistor probe (orange filled circles). The error bars in the larger plot show the range of temperature offsets corresponding to the $\pm 0.3^{\circ} \mathrm{C}$ calibration error of the temperature standard. From room temperature to $-33^{\circ} \mathrm{C}$ as measured at the base of the well, the average cooling rate is $-0.87^{\circ} \mathrm{C} \mathrm{min}-1$. Inset shows cooling performance of the bath coolant and the temperature within the well and gas above well over $3276 \mathrm{~s}$ measured by thermistor probes. The average cooling rate at the base of the well during the time period from 0 to $-27^{\circ} \mathrm{C}$, however, is $-0.69^{\circ} \mathrm{C} \mathrm{min}^{-1}$ because the cooling rate slows as the refrigerated cooling bath approaches its minimum temperature.

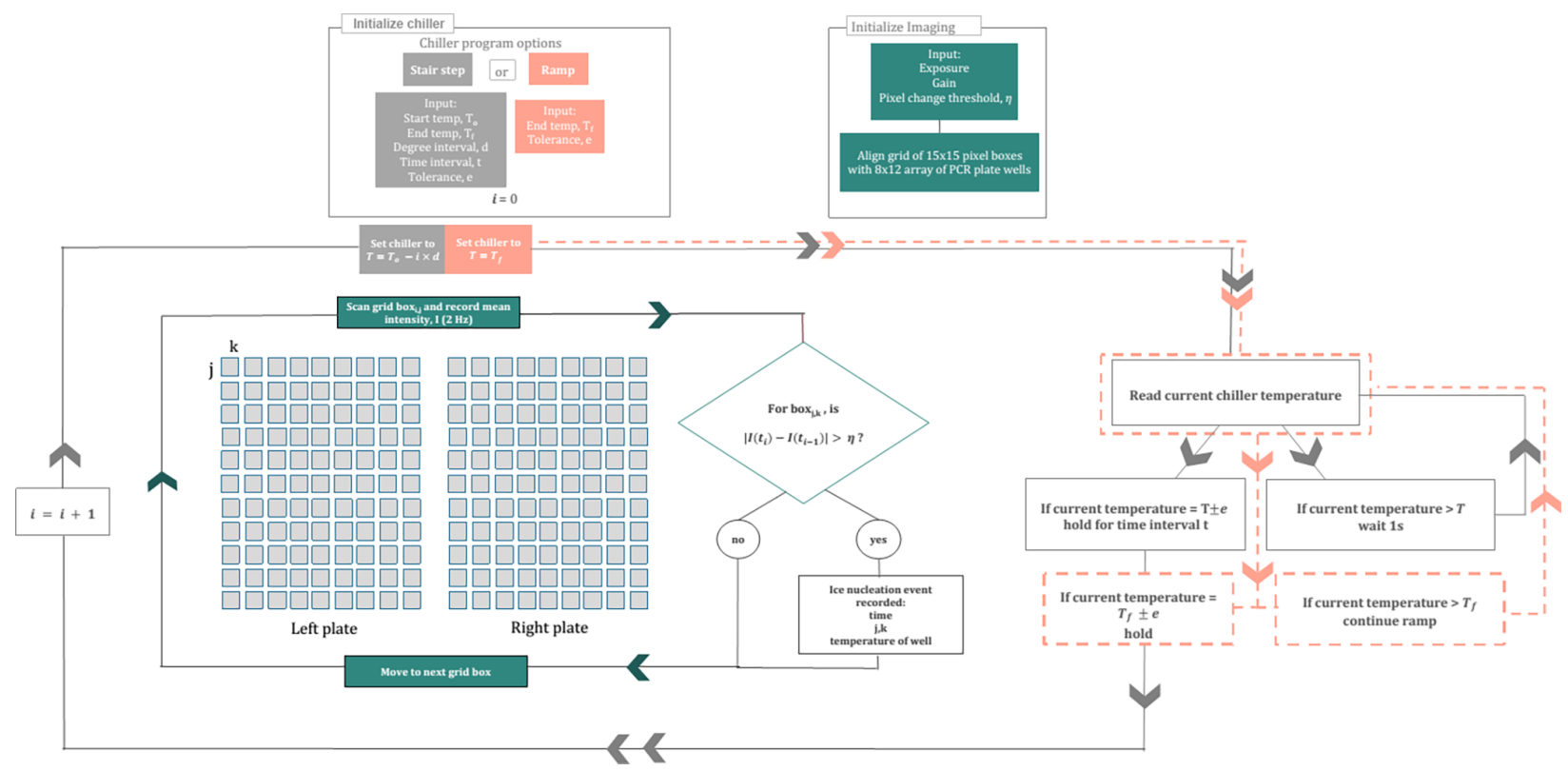

Figure 4. Flow chart describing algorithm for detection of freezing events using camera and lights to leverage optical properties of phase change from water to ice. Grey and pink are used to indicate the "stair step" and "ramp" temperature control of the chiller (for details see main text). Green is used to indicate imaging section of the algorithm for detection of freezing events.

uid wells. Thus, the probe must be placed outside the well volume but in a region of the well block that is thermally homogenous with the sample. Alternatively, if the heat transfer characteristics of the system are resolved, the thermal probe could be placed anywhere in the block where the offset in temperature between the probe's location and the sample well volume is quantified. The sample volume itself must be thermally homogenous because, if the sample volumes were stratified, a freezing event could be triggered in any of the 
stratified well layers depending on its temperature and the buoyancy of the ice nucleating entity.

In order to address the thermal properties of the aluminum block and well-plate system, a finite-element-analysis-based heat transfer simulation was developed using the 3-D design software SOLIDWORKS to investigate the homogeneity of temperature within the $50 \mu \mathrm{L}$ sample volumes throughout the cooling process and to determine the optimal placement and number of thermistors needed to resolve the temperature of each well. As shown in Fig. 6, a 3-D model of the AIS was designed using the dimensions and material properties of the actual instrument components. In finite-element-analysis heat transfer simulations, a mesh is applied to the modeled object such that, with a given initial temperature and/or heat source at the boundaries, rates of heat transfer and temperature are computed iteratively until solutions converge on the user-defined mesh. Meshing becomes more computationally expensive over curved or complex surfaces, and because the AIS well blocks contain 192 wells each with a curved inner surface, a cut of the upper left quadrant shown in Fig. 6a was made in the 3-D model to reduce computation time. In Fig. 6a, the two aluminum 96-well blocks are shown with the PVC splash guard, and the dashed red line in the upperleft corner represents the modeled cut in the well block. Figure $6 \mathrm{~b}$ and $\mathrm{d}$ show a close-up of the well block quadrant featured in the model, including the aluminum well block, the polypropylene sample tray, and a $50 \mu \mathrm{L}$ sample of water. A pocket of gas between the sample tray and the well block is also modeled due to the slightly imperfect fit of the tray to the well block in the actual instrument. The simplifying modeling cut was justified by making measurements of the horizontal distribution of temperature through the two boundaries of the well region: the nitrogen gas above the well region and the coolant bath, which by design maintains a homogenous temperature throughout the coolant volume. The homogeneity of temperature in the coolant bath was verified using a calibrated thermometer (Checktemp Pocket Thermometer, Hanna Instruments, accuracy $\pm 0.3^{\circ} \mathrm{C}$ from -20 to $90^{\circ} \mathrm{C}$ ). To investigate the horizontal distribution of the temperature of gas across the surface of the well block, four thermistors were placed in the $5 \mathrm{~cm}$ headspace between the well block surface and the plexiglass lid during repeated cooling processes, and the thermistor temperature was monitored while systematically moving the thermistors through the headspace. The temperature of the nitrogen gas in the headspace was found to be homogenous across the plate within $\pm 0.3^{\circ} \mathrm{C}$ (within the error of the calibrated temperature probe).

The horizontal gradient of temperature is constrained by the homogenous temperature across the bottom surface of the well block and a temperature difference of $\max \pm 0.3^{\circ} \mathrm{C}$ across the top surface. The vertical gradient of temperature through the well block, disposable sample tray, and sample volume is not practically measurable and requires resolution through heat transfer simulations in order to determine where probes should be placed to measure temperature of the wells. The larger hole on the left side of the sample well in Fig. 6a and $b$ is where the thermal probes were placed in the original AIS design.

The mesh used is shown in Fig. 6c and was applied using the SOLIDWORKS standard mesh solver. It is composed of discrete, tetrahedral elements that are connected at the three nodes such that they converge through all components in the modeled system. Generally, an aspect ratio around 1 for each element is ideal; for the mesh applied in the heat transfer simulations, $99.1 \%$ of the mesh elements have an aspect ratio of less than 3, and $0.00 \%$ of mesh elements have an aspect ratio greater than 10 . Four Jacobian points, or nodes at the midpoint of element sides, were applied to each element to align with curvature more effectively with linear elements, and the mesh took $1 \mathrm{~min}, 56 \mathrm{~s}$ to converge.

\subsection{Setup of the heat transfer simulation}

The nitrogen and coolant fluid in thermal contact with the sample volumes and well block, respectively, form the thermal boundaries of the simulation. Thus, to quantify the boundary conditions for the heat transfer simulation, temperature measurements were made of the gas temperature above the sample volumes and the coolant temperature during a ramp cooling process, in which the refrigerated bath circulator ran from room temperature to $-33^{\circ} \mathrm{C}$ at an average cooling rate of $-0.87^{\circ} \mathrm{C} \mathrm{min}-1$ (see Fig. 3). In addition, a hole was drilled into the aluminum block so that a thermistor could be placed directly underneath a sample well.

Once the thermistor was placed in the block, the hole was sealed with acrylic caulk to prevent coolant fluid from entering the well region, and heat sink compound was applied to the thermistor so that it was in thermal contact with the aluminum block and the disposable sample tray. In Fig. 3, the temperature at three locations within the AIS is shown after measurement throughout a "ramp" cooling process from 15 to $-33^{\circ} \mathrm{C}$ : (1) the coolant in contact with the bottom surface of the well block; (2) the gas above the sample volume, or headspace gas; and (3) directly below the sample well. The measurements of temperature of the gas above the sample volume and coolant over $3276 \mathrm{~s}$ of cooling are applied as boundary conditions in the heat transfer simulation. The larger plot in Fig. 3 shows the warm temperature offset of the headspace gas from the measured temperature at the well base, and the inset plot shows temperature changes in time, at the three locations over the ramp cooling cycle. The headspace gas and coolant temperature data are applied as boundary conditions in the simulation. Figure 3 shows that the air above the well region is a maximum of $+4.19^{\circ} \mathrm{C}$ warmer than the well base, despite the chilled nitrogen pumped over the well region, because the system is imperfectly insulated from the room temperature environment and because there is a slight warming of the gas before it enters the headspace (as described in Sect. 2.2). An acrylic 


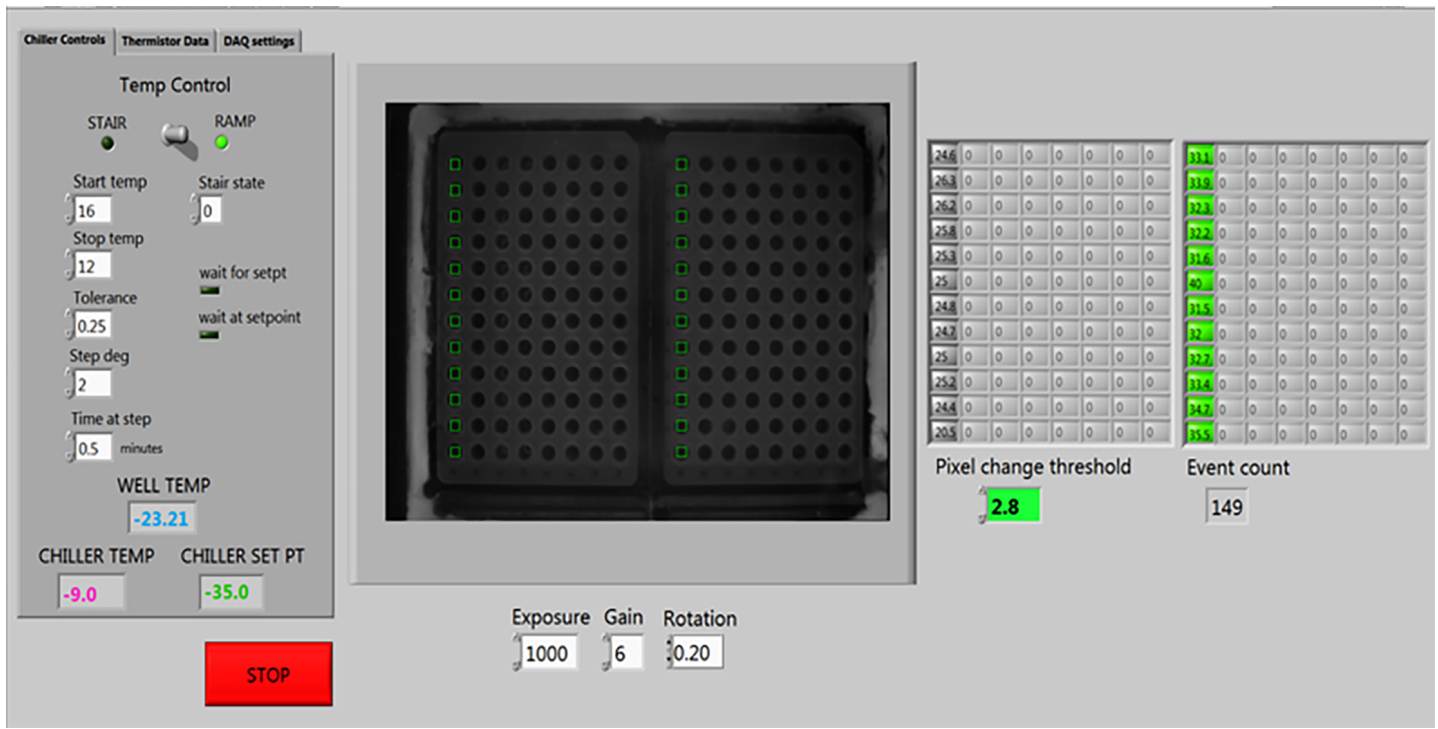

Figure 5. A screenshot of the AIS user computer interface, with chiller controls and well temperature readings on the left and video stream of image of wells in the middle. The detected freezing events are highlighted in green and displayed in the well matrix diagram on the right.
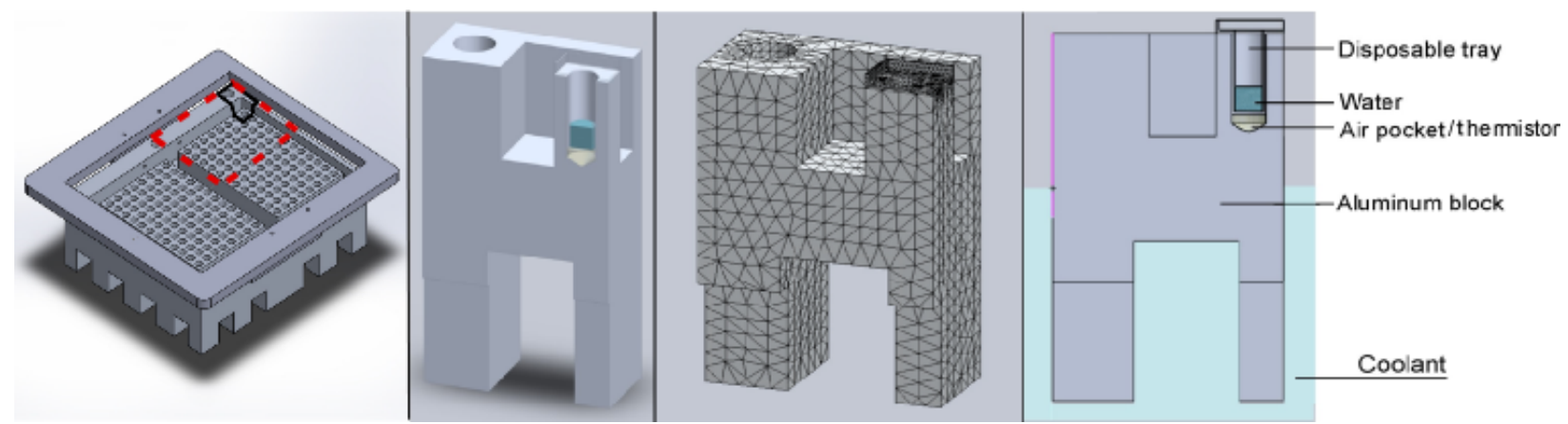

Figure 6. Schematic of cut in well block made for heat transfer simulation and mesh applied. (a) Well block and cover with red dashed line to indicate where simplifying cut (see Figs. 7 and 8) in assembly was made for the heat transfer simulations. Black line indicates the section of well block that is featured in (b), (c), and (d) to show all components modeled in the simulations. (b) Isometric, sectional view of the block corner. (c) Image of mesh applied using SOLIDWORKS standard mesh solver (see Sect. 3.1 for details). (d) Isometric, flat sectional view of the block corner with labels to indicate materials parameterized in the heat transfer simulations shown in Figs. 7 and 8.

plate covers the wells as shown in Fig. 1, but the system is not thermally isolated from the environment.

Figure $6 \mathrm{~d}$ shows each of the components considered in the model: the aluminum well block, the disposable sample tray, the gas pocket in the gap between bottom of the sample tray and the well block, and the $50 \mu \mathrm{L}$ sample water volume. The coolant and the headspace gas were considered as variable thermal loads to the system rather than included as components. Two types of heat transfer were considered during the model analysis: conductive and convective. All of the components shown in Fig. 6d are considered to be bonded, or treated as if heat transfer by conduction occurs in a continuous manner. Heat transfer by conduction is computed at each element of the mesh by the following equation:

$Q_{\text {conduction }}=k A\left(T_{\text {hot }}-T_{\text {cold }}\right)$, where $Q_{\text {conduction }}$ is the rate of heat transfer in watts, $k$ is thermal conductivity of the component, $A$ is the heat transfer area defined by the mesh, and ( $\left.T_{\text {hot }}-T_{\text {cold }}\right)$ is the temperature difference between the two mesh elements considered. Thermal conductivity, $k$, is determined by the material of the component. Values of $k$ used in the simulation are shown in Table 1.

At all interfaces where the model is in contact with headspace gas, heat transfer by convection is considered. For heat transfer by convection, Eq. (3) is applied at each element:

$Q_{\text {convection }}=h A\left(T_{\mathrm{s}}-T_{\mathrm{f}}\right)$,

where $Q_{\text {convection }}$ is the rate of heat transfer from a body to a fluid in watts, $h$ is the heat transfer coefficient in $\mathrm{W} \mathrm{m}^{-2} \mathrm{~K}$, 
Table 1. Elements and properties used in heat transfer simulation.

\begin{tabular}{llrr}
\hline Components & Material & $k^{\mathrm{a}}\left(\mathrm{W} \mathrm{mK}^{-2}\right)$ & $h^{\mathrm{b}}\left(\mathrm{W} \mathrm{m}^{-2} \mathrm{~K}\right)$ \\
\hline Well block & Aluminum 1060 alloy & 200 & 25 \\
Disposable sample tray & Polypropylene & 0.117 & 25 \\
Gas pocket & Air & 0.027 & $\mathrm{n} / \mathrm{a}$ \\
Liquid INP sample & Water & 0.5 & 191 \\
\hline
\end{tabular}

${ }^{a}$ Davis (1998). ${ }^{\text {b }}$ Yousef et al. (1982). See Sect. 3.2 for calculation of $h$ for liquid sample.

Note: both $k$ and $h$ are temperature dependent but were used as constants in the simulation due to the

insensitivity of the simulation between 0 and $-30^{\circ} \mathrm{C} . \mathrm{n} / \mathrm{a}=$ not applicable

and $\left(T_{\mathrm{S}}-T_{\mathrm{f}}\right)$ is the difference in temperature between the surface of the body and the fluid. $A$ is the same as above in Eq. (2). The convection of both the gas and the water in the model was considered natural convection rather than forced. Typical ranges for the heat transfer coefficient $h$ for natural convection of air are $5-25 \mathrm{~W} \mathrm{~m}^{-2} \mathrm{~K}$ (Yousef et al., 1982). The model output was insensitive to this range of coefficient variability, and a value of $25 \mathrm{~W} \mathrm{~m}^{-2} \mathrm{~K}$ was used. The range of $h$ for natural convection of water, however, is much larger: 2-3000 W m ${ }^{-2} \mathrm{~K}$ (VDI-Gesellschaft Energietechnik, 2013), so $h$ was estimated by approximating the wells as two vertical plates; calculating the Nusselt number $\mathrm{N}$; and using $h=N k / H$, where $H$ is the height of the plates. $N$ was calculated using Eq. (4) for laminar flow (Churchill and Chu, 1975):

$N=0.68+\frac{\left(0.670 \mathrm{Ra}^{1 / 4}\right)}{\left(1+\left(\frac{0.492}{P r}\right)^{9 / 16}\right)^{4 / 9}}$.

$R a$ and $P r$ are the Rayleigh and Prandtl number (Holman, 2009), respectively, where

$R a=\frac{g \beta\left(T-T_{\infty}\right) D^{3}}{v^{2}} \cdot \operatorname{Pr}$

and $\operatorname{Pr}=v / \alpha$.

$\beta$ is the coefficient of thermal expansion, $g$ is the acceleration due to gravity, $T$ is the temperature of the water volume, $T_{\infty}$ is the temperature of the air at the surface of the water volume, $D$ is the diameter of the well as measured at the top of the well of the disposable sample tray, $v$ is dynamic viscosity, and $\alpha$ is the thermal diffusivity. Since $\beta$, $v, \alpha$, and $k$ are temperature-dependent properties, and $h$ is of interest over the supercooled range from 0 to $-25^{\circ} \mathrm{C}, N$ and $h$ were calculated at $-5,-15$, and $-25^{\circ} \mathrm{C}$, using corresponding values of $\beta, v, \alpha$, and $k$ (Kell, 1975; Dehaoui et al., 2015; Benchikh et al., 1985; Biddle et al., 2013), which are shown in Table 2. Thus, $h$ was estimated to be 161, 191, and $202 \mathrm{~W} \mathrm{~m}^{-2} \mathrm{~K}$ at $-5,-15$, and $-25^{\circ} \mathrm{C}$, respectively. Within the range $161-202 \mathrm{~W} \mathrm{~m}^{-2} \mathrm{~K}$, the model was insensitive, and a constant value of $191 \mathrm{~W} \mathrm{~m}^{-2} \mathrm{~K}$ was used throughout the simulations.

The simulation was run over $3276 \mathrm{~s}$ with two different sets of boundary conditions representing the coolant fluid and headspace gas temperatures. In the first simulation, the coolant fluid temperatures from Fig. 3 were applied, but the difference between the temperature of the headspace gas and that of the well base was multiplied by 2 in order to approximate inefficient cooling of headspace gas. In the second simulation, the gas and coolant temperatures were applied directly from the coolant fluid and headspace gas temperature in Fig. 3. The first condition has warmer headspace gas temperatures than those that were measured during the cooling process on the actual instrument in Fig. 3

\section{Results}

\subsection{Simulation results}

The results of the heat transfer simulation for the warmer headspace gas condition and the measured gas and coolant temperature conditions are shown in Figs. 7 and 8. Figure 7 shows a graphical time series of the heat transfer simulation with the doubling of the offset between the well base and the warmer gas above the well region. The heat distribution is shown in 12 time steps at 273 s intervals over a 3276 s simulation, with the coolant fluid cooling from 15 to $-33^{\circ} \mathrm{C}$ over that period (i.e., $-0.87^{\circ} \mathrm{C} \min ^{-1}$ ). At the top of Fig. 7, an isometric view of the well block at $1638 \mathrm{~s}$ is shown, and to the right is a detailed view of the well. The results show the stratification of temperature in the sample volume itself, ranging from $-13.8^{\circ} \mathrm{C}$ at the skin of the sample volume to $-14.3^{\circ} \mathrm{C}$ at the bottom of the sample volume. These results demonstrate that the temperature difference of $+6^{\circ} \mathrm{C}$ between the well and the headspace gas is too large to maintain homogenous temperature within the liquid sample volume, which then becomes stratified by $0.5^{\circ} \mathrm{C}$. The degree of stratification through the duration of the simulation is shown in Fig. S2 in the Supplement, reaching a maximum of $0.6^{\circ} \mathrm{C}$.

Figure 8 shows a graphical time series of the heat transfer simulation with the measured AIS headspace gas temperature and coolant bath temperature conditions from Fig. 3. With an offset between the base of the well and the headspace gas temperature of $+3.0^{\circ} \mathrm{C}$, stratification has significantly decreased to $0.1^{\circ} \mathrm{C}$ from top to bottom of the sample volume, which is within the error of the thermal probe (see Fig. S2). 
Table 2. Constants used in calculation of heat transfer coefficient $h$ for water in natural convection from -5 to $-30^{\circ} \mathrm{C}$.

\begin{tabular}{rrrrrrr}
\hline Water temperature & $\begin{array}{r}\text { Gas temperature } \\
T_{\infty}\left({ }^{\circ} \mathrm{C}\right)\end{array}$ & $\begin{array}{c}\beta^{\mathrm{a}}\left(\mathrm{K}^{-1}\right) \\
\times 10^{-6}\end{array}$ & $v^{\mathrm{b}}\left(\mathrm{m}^{2} \mathrm{~s}^{-1}\right)$ & $\alpha^{\mathrm{c}}\left(\mathrm{m}^{2} \mathrm{~s}^{-1}\right)$ & $\begin{array}{r}k^{\mathrm{d}} \\
\times 10^{-6}\end{array}$ & $\begin{array}{r}h \\
\left({ }^{\circ} \mathrm{C}\right)\end{array}$ \\
-5.0 & -1.6 & -168.6 & 2.0026 & 1.30 & 0.520 & 160.8 \\
-15.0 & -10.3 & -450.3 & 3.0707 & 1.20 & 0.500 & 191.0 \\
-30.0 & -23.4 & -1400.0 & 7.9703 & 1.05 & 0.450 & 201.6 \\
\hline
\end{tabular}

${ }^{\mathrm{a}}$ Kell (1975). ${ }^{\mathrm{b}}$ Dehaoui (2015). ${ }^{\mathrm{c}}$ Benchikh (1985). ${ }^{\mathrm{d}}$ Biddle (2015).

The results also show that the distribution of heat throughout the well block requires careful placement of the temperature probe such that the temperature of the probe location is accurately indicating the temperature of the sample volume. In each of the simulations, the sample water volume comprises the warmest body in the model assembly. Throughout the modeled assembly, the temperature in the gas pocket underneath the well of the polypropylene disposable tray was the region closest in temperature to the sample volume, albeit still colder by as much as $-1.8^{\circ} \mathrm{C}$. Due to strong temperature gradients between the water sample and the immediately surrounding aluminum block, small variations in probe location can result in disproportionately large temperature offsets from the sample volume. At $1638 \mathrm{~s}$ in the second simulation, which applies the gas and coolant temperature conditions as measured on the AIS (Fig. 3), the temperature decreases $1.8^{\circ} \mathrm{C}$ from base of the well of the polypropylene disposable tray through the gas pocket to the aluminum surface of the well block over a distance of $2.5 \mathrm{~mm}$, resulting in an offset of $-1.6^{\circ} \mathrm{C}$ between the average temperature of the air pocket and that of the sample volume. This could be caused by the high specific heat of the water volume relative to the aluminum, and the insulating thermal properties of the polypropylene tray could be responsible for the strong temperature gradient. In the current design of the AIS, the thermal probe is located in this gas pocket, and the simulation results suggest that at this location there could be up to a $-1.8^{\circ} \mathrm{C}$ cold bias in the INP freezing temperature measurements. Thus, during ramping of the coolant bath from room temperature to $-33^{\circ} \mathrm{C}$ at about $-0.87^{\circ} \mathrm{C} \mathrm{min}^{-1}$, there is nowhere to place a probe in the aluminum block where the temperature perfectly matches that of the liquid sample volume (within $\ll 1^{\circ} \mathrm{C}$ ). The offset in temperature between the probe and the sample temperature was quantified so that recorded temperatures can be adjusted accordingly.

In order to verify the simulation output so that offsets found can be applied quantitatively to freezing temperature measurements, simulated temperatures were checked against measurements that were independent of the simulation. Since the entire surface of the system was constrained by boundary conditions in the simulation, the measurements from inside of the well block at the well base (shown in Fig. 3) were used for comparison with the simulation output at the same location. Results of the comparison over the 12 time steps of the
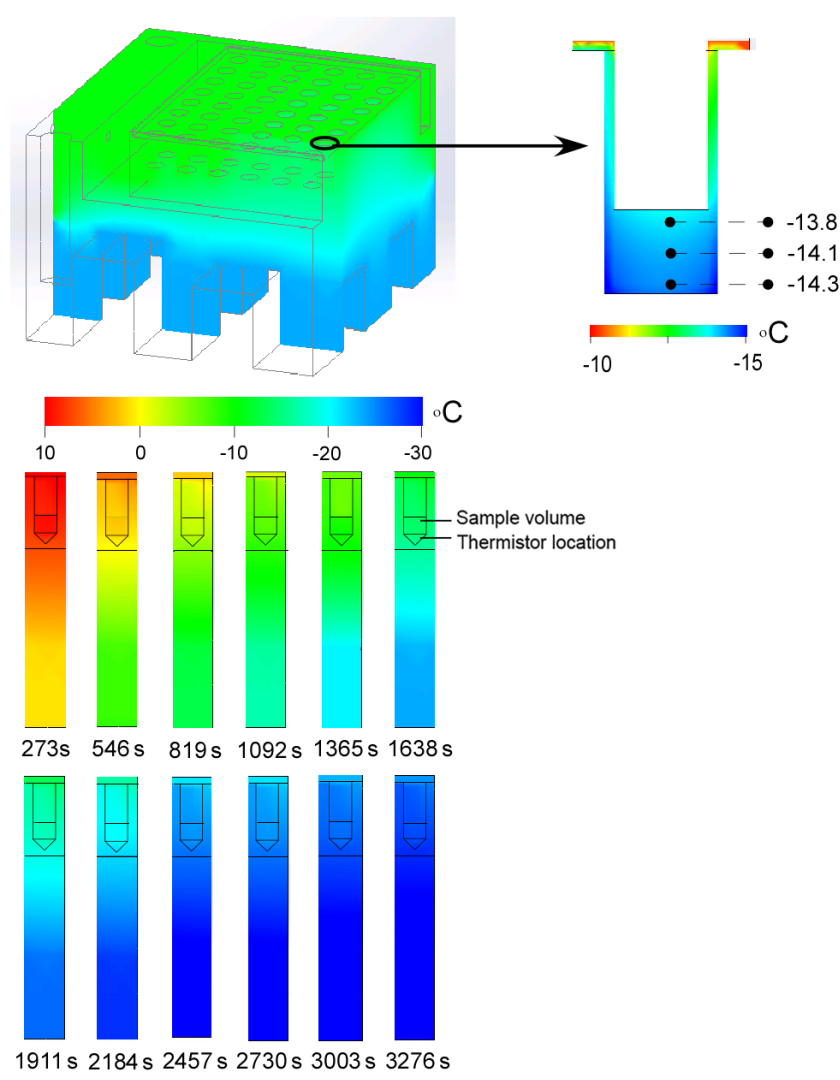

Figure 7. Graphical time series of the heat transfer simulation. Top shows isometric view of the well block (top left quarter) at $t=$ $1638 \mathrm{~s}$. Top right shows detailed plane view of well at $t=1638 \mathrm{~s}$. Dashed lines indicate temperature of water in the well at three points. Colors indicate temperature referenced by the scale below. Twelve time steps at $273 \mathrm{~s}$ intervals show temperature distribution within the well block shown below. The average cooling rate over this time period is $-0.87^{\circ} \mathrm{C} \mathrm{min}^{-1}$. Results show the stratification of temperature in the sample volume due to warmer air above the well region (see Sect. 3.2 for details).

simulation are shown in Fig. S1. At subzero temperatures, the maximum difference between the measured and simulated temperatures was $0.6^{\circ} \mathrm{C}$ at $t=819 \mathrm{~s}$, decreasing to values below the error of the thermistor for most of the simulation. $\pm 0.6^{\circ} \mathrm{C}$ is assumed to be the uncertainty of the simulation. The measured temperature was consistently slightly warmer 


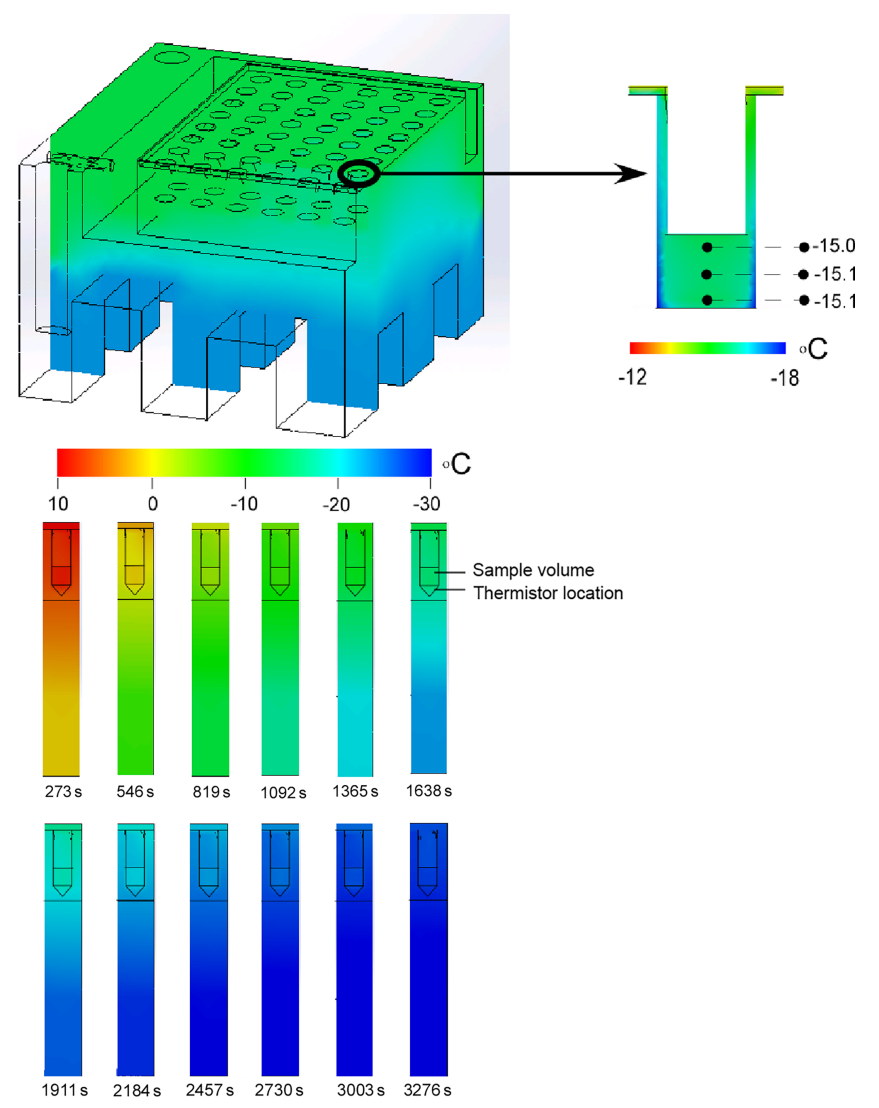

Figure 8. Graphical time series of the heat transfer simulation showing the effects of increasing thermal homogeneity in the cooling environment by efficiently cooling headspace gas on performance of the well block. As in Fig. 7, the top shows isometric view of the well block at $t=1638 \mathrm{~s}$. Dashed lines indicate temperature of water in the well at three points. Colors indicate temperature referenced by the scale below. Twelve time steps at $273 \mathrm{~s}$ intervals showing temperature distribution within the well block shown below. The average cooling rate over this time period is $-0.87^{\circ} \mathrm{C} \mathrm{min}{ }^{-1}$. Results show the decreased stratification of temperature in the well due to cooler air above the well region (air temperature offset varied approximately $+2-4{ }^{\circ} \mathrm{C}$ from the bath coolant temperature as shown in Fig. 3).

than the simulated temperature, possibly because the hole drilled into the aluminum well block was not modeled. In the second simulation using measured boundary conditions, the average temperature of the sample volume was compared with the average temperature of the air pocket in which the thermistor is placed throughout the $3276 \mathrm{~s}$ simulation (see Fig. S3), in order to quantify the offset between the thermistor and the sample. The air pocket temperatures are consistently colder than the sample volume temperatures, ranging from -1.8 to $-1.2^{\circ} \mathrm{C}$ over the $3276 \mathrm{~s}$ simulation. Offsets in temperature between the 192 wells also exist in the AIS and are shown in Fig. S4. Sample volumes in wells near the outer perimeter are up to $+2.2{ }^{\circ} \mathrm{C}$ warmer than sample volumes near the center of the well block. Detailed analyses of the offsets along the $x$ and $y$ axis over the 3276 s simulation are not shown because there is currently only one thermistor embedded in the well block, so verification of the simulation's temperature gradient in $x$ and $y$ was not possible without further modifications to the well block. In the future, additional thermistors embedded within the well block can be used to verify the simulation output so that measurements can be adjusted with offsets due to the gradient in $x$ and $y$ as well as $z$. However, the maximum offset found between wells in $x$ and $y,+2.2^{\circ}$, will be represented as the uncertainty associated with the measurements reported in the following sections.

\subsection{Automated Ice Spectrometer performance: comparison with six other immersion mode ice nucleation measurement techniques}

The accuracy of the AIS INP concentration measurements were evaluated using a standard, well-characterized test dust that has previously been used to compare immersion mode ice nucleation measurement techniques, illite NX (Arginotech, NX nanopowder) (Hiranuma et al., 2015). A suspension of dust and Milli-Q ultrapure water was prepared in a sterile $50 \mathrm{~mL}$ centrifuge tube (Corning) using a sample from the same batch of illite NX used in Hiranuma et al. (2015), a study of 17 immersion mode ice nucleation measurement techniques. Twenty milligrams of illite NX was immersed in $500 \mathrm{~mL}$ of ultrapure water, resulting in a $4.0 \times 10^{-3}$ wt $\%$ solution. Two more dilutions were made by immersing $25 \mathrm{mg}$ of illite $\mathrm{NX}$ in $50 \mathrm{~mL}$ of ultrapure water and diluting again by factors of $1 / 10$ and $1 / 100$, resulting in solutions of $5.0 \times 10^{-2}$ and $5.0 \times 10^{-3} \mathrm{wt} \%$, respectively. A final solution was prepared by starting with $300 \mathrm{mg}$ in $50 \mathrm{~mL}$ of ultrapure water and then diluting by factors of $1 / 100$ and $1 / 1000$, resulting in a solution of $6.0 \times 10^{-6} \mathrm{wt} \%$. For comparison, in Hiranuma et al. (2015), droplet assays were intercompared using illite NX suspensions of varying dilutions within the range of $3.1 \times 10^{-6} \mathrm{wt} \%$ to $1.0 \mathrm{wt} \%$. Higher concentrations of illite NX solution were not measured using the AIS because the automation software requires an optically clear solution to detect freezing events. Fifty-microliter aliquots of the suspension were loaded into 24 wells of the disposable sample tray (Life Science Products ${ }^{\mathrm{TM}}$ 96-well PCR plates), and 24 adjacent wells were filled with $50 \mu \mathrm{L}$ aliquots of Milli-Q water. Prior to loading, the plexiglass lid was cleaned with an isopropyl-alcohol-based surface cleaner, rinsed three times with Milli-Q, and dried with clean compressed air, and nitrogen was pumped over the well region at $0.25 \mathrm{~L} \mathrm{~min}^{-1}$ for $20 \mathrm{~min}$ to purge the lines of any dust. The loaded and covered sample was then cooled from room temperature to $-27^{\circ} \mathrm{C}$ (with an average cooling rate of $-0.87^{\circ} \mathrm{C} \min ^{-1}$ ), at which point the Milli-Q water had frozen in all wells. The experiment was repeated four times. Freezing events were detected using the automation software and, the time of freezing, well temperature, and sample number were recorded into an ASCII file for further analysis. 
Cumulative concentration of INPs per volume per $0.25^{\circ} \mathrm{C}$ were calculated using Eq. (1) (Vali, 1971). In order to compare directly with Hiranuma et al. (2015), cumulative concentrations of INPs were converted into a surface site density, $n_{\mathrm{s}, \mathrm{BET}}$. The specifics of the parameterization are in Hiranuma et al. (2014), but briefly, the parameterizations are based on BET (Brunauer-Emmet-Teller) (Brunauer et al., 1938) $\mathrm{N}_{2}$ adsorption-based specific surface area (SSA) in which the particle surface area is measured based on the quantities of a variety of gases that form monolayers on the surface of the particle. The SSA of the illite NX sample used in Hiranuma et al. (2015) was $124 \mathrm{~m}^{2} \mathrm{~g}^{-1}$, and the mass concentration $(\mathrm{m})$ of the four illite NX solutions processed in the AIS ranged from $6.0 \times 10^{-6}$ to $5.0 \times 10^{-2} \mathrm{~g} \mathrm{~mL}^{-1}$. The AIS measurement results in terms of cumulative INPs per volume were converted to the surface site density, $n_{\mathrm{s}, \mathrm{BET}}$, using the mass concentration and specific site density as follows:

$n_{\mathrm{s}, \mathrm{BET}}=\frac{\left(\frac{\mathrm{INPs}}{\mathrm{mL}}\right)}{\mathrm{SSA} \cdot m}$.

In Fig. 9, the measured illite NX spectra are shown with 6 of the 17 total ice nucleation measurement techniques from Hiranuma et al. (2015). These were similar freezing or droplet assay techniques: the CSU-IS, the NIPI, FRIDGE (in immersion mode), NC-State CS, BINARY, and the CU-RMCS. The six instruments made wet-suspension-based measurements of illite NX in ultrapure water rather than dry-particlebased measurements and thus should more directly compare to those of the AIS. Temperature offsets between the thermistor and the sample volumes due to the consistently colder location of the thermistor, $\pm 1.8^{\circ} \mathrm{C}$, and the warmer wells near the perimeter of the well block, $\pm 2.2^{\circ} \mathrm{C}$ (see Sect. 4.1), are represented in the error bars on the AIS measurements. The ice nucleation surface site density spectra of the six measurements fall within a range of about $5^{\circ} \mathrm{C}$, and the Automated Ice Spectrometer measurements compare favorably to those of the other six techniques through its final temperature of $-25^{\circ} \mathrm{C}$. However, the AIS measurements fall on the warmer side of the temperature spectrum from -10 to $-25^{\circ} \mathrm{C}$. Based on the results of the heat transfer simulations in Sect. 4.1, differences in the cooling process type (stair step or ramp), location of temperature probe or method of freezing temperature measurement could have strong influences on reported freezing temperatures. These factors might account for some of the $8^{\circ} \mathrm{C}$ (or $5^{\circ} \mathrm{C}$ for wet-suspension droplet assay techniques) spread in spectra reported in Hiranuma et al. (2015).

\section{Discussion}

The immersion mode ice spectrometer (original configuration in Hill et al., 2014 and latest design described in Hiranuma et al., 2015) was modified to fit inside a refrigerated circulating coolant bath and automated using a software controlled camera. Older versions of the immersion mode ice spectrometer were designed with the aluminum well blocks external to the refrigerated circulator bath, and the coolant fluid was pumped through heat exchange plates encasing the aluminum well blocks for cooling via external copper tube plumbing. The operator observed and recorded well freezing manually. Modifications to the instrument increased thermal homogeneity across the well block by immersing well blocks directly in the coolant bath. Automation enables more objective and instantaneous recording of well-freezing events and frees the operator from having to constantly monitor sample processing.

The heat transfer properties of the AIS were characterized using finite-element-analysis heat transfer simulations, with measured temperatures of the well block headspace gas and the coolant bath applied as boundary conditions. Heat transfer by conduction and convection was considered.

The results of the simulations showed that efficient cooling of the well block headspace, with a maximum $+4{ }^{\circ} \mathrm{C}$ offset between the base of the well and the headspace gas or $+11^{\circ} \mathrm{C}$ between the coolant bath and the headspace gas, is necessary to ensure that the liquid sample volume is unstratified within the error of the thermal probe, $\pm 0.2^{\circ} \mathrm{C}$, so that the well-freezing temperature is representative of the population INPs in the well. The results also demonstrate a strong temperature gradient from the sample volume to the polypropylene and aluminum immediately surrounding the sample, of up to $-1.8^{\circ} \mathrm{C}$ in the $2.5 \mathrm{~mm}$ gap. Thus the temperature measurement in the AIS is highly sensitive to the location of the thermal probe. In the simulation, the only region with a temperature consistent with the sample volume was the top of the gas pocket between the bottom of the polypropylene disposable tray and the aluminum block. However, a thermistor probe cannot physically fit in this small region, so INP freezing temperature measurements are likely biased by the thermistors contact with the aluminum block. An offset between the thermistor location and the sample volume was quantified, first by verifying the simulation output using a thermistor embedded in the well block (see Fig. S1), then using the simulation output to determine the offset to apply to the recorded measurements. For other immersion mode droplet assay INP measurement techniques, variation in heat transfer properties and thermal probe placements may result in higher or lower accuracy of INP freezing temperature measurement, but the sensitivity of the temperature gradient within the droplet to the thermal heterogeneity of its cooling environment, as well as that of the temperature measurement to thermal probe placement, motivates careful study of the effect of heat transfer properties of the various techniques. The heat transfer simulations applied here could support investigations of bias in temperature measurement for INP measurement techniques, enable higher accuracy in INP freezing temperature measurements, and ultimately help decrease disparities between various instruments. INP concentrations applied in cloud and climate models must be accurate within an order of 10 to avoid propagation of error 


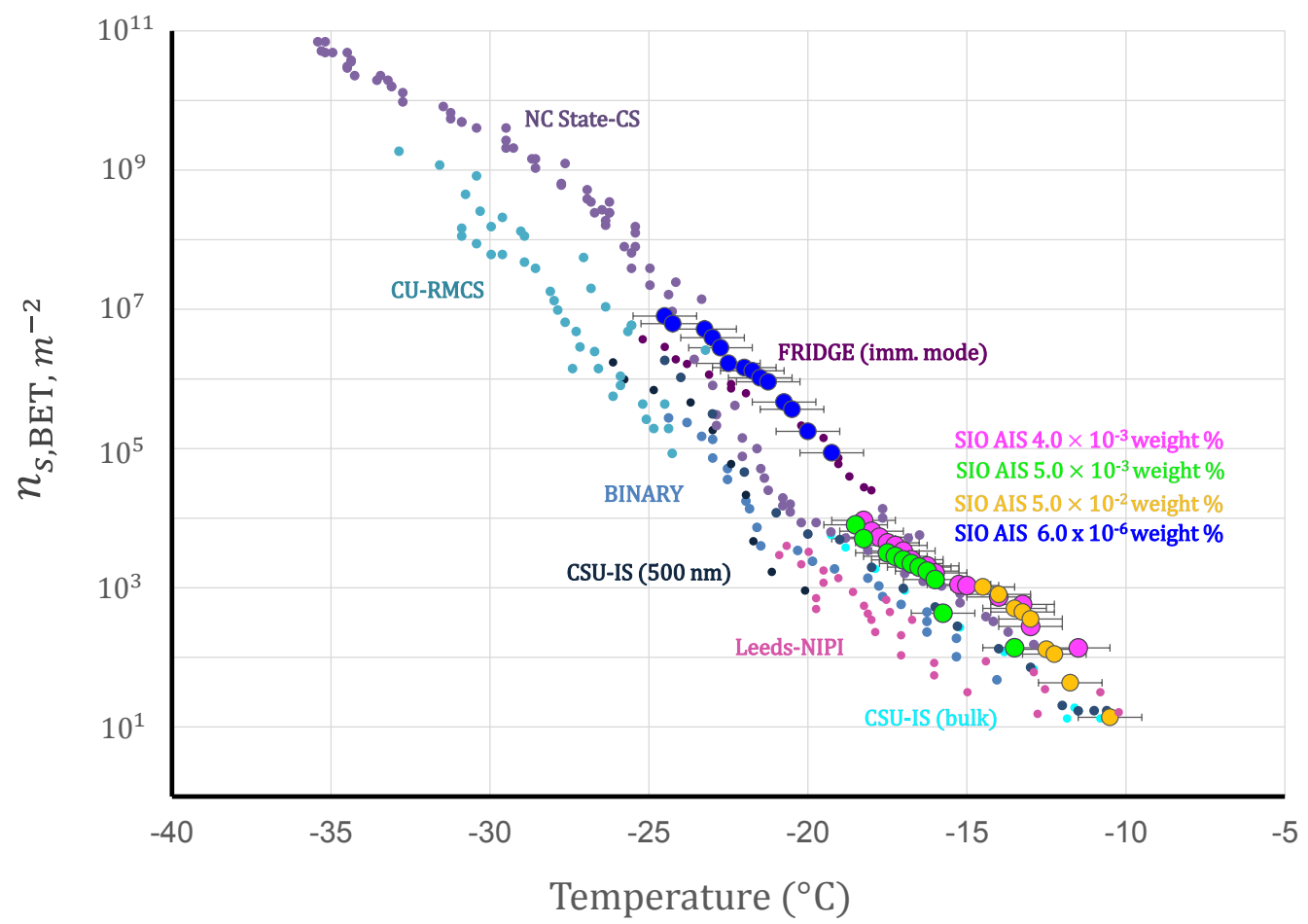

Figure 9. Immersion freezing spectra of illite NX particles in terms of $n_{\mathrm{s}, \mathrm{BET}}(T)$ for comparison of SIO AIS against six other immersion mode techniques reported (see Hiranuma et al., 2015). $n_{\mathrm{S}, \mathrm{BET}}$ is used to estimate ice nucleation surface site density from an $\mathrm{N}_{2}-$ adsorption-based specific surface area (Hiranuma et al., 2015). CSU-IS (500 nm) represents measurements made on illite NX particles that were mobility-diameter-size-selected, whereas all other measurements reported were of bulk illite NX samples. Four different dilutions of illite NX suspensions were measured by the SIO AIS: $4.0 \times 10^{-3} \mathrm{wt} \%, 5.0 \times 10^{-3} \mathrm{wt} \%, 5.0 \times 10^{-2} \mathrm{wt} \%$, and $6.0 \times 10^{-6}$ wt $\%$. SIO AIS measurements fall on the warm side of the spectra.

leading to significantly different cloud properties (Phillips et al., 2003), and as measurements typically show INP concentrations increasing with decreasing temperature in complex multi-exponential functions (Hiranuma et al., 2015), an $8^{\circ} \mathrm{C}$ uncertainty in freezing temperature measurement could result in vast differences in model output. Heat transfer simulations could prove particularly useful in studies of the role of varied cooling rates on assessment of ice nucleation activity in different devices due to the stochastic or time-dependent nature of droplet freezing at a given temperature. In such an investigation, it is important to separate the impact of time dependence of the ice nucleating entity from variations due to temperature gradients between the location of the thermal probe and the sample volume.

Fast cooling of samples $\left(>1{ }^{\circ} \mathrm{Cmin}^{-1}\right)$ has been discussed as a potential source of stratification of temperature between the substrate and the droplets, or within the droplets; conversely, that chilled nitrogen in the headspace might not be necessary to avoid stratification (Tobo, 2016). However, the heat transfer simulation results below show that, even with cooling rates below $1{ }^{\circ} \mathrm{C} \mathrm{min}-1$, stratification within the sample volume can occur and that the temperature of nitrogen gas in the headspace may play a significant role in controlling temperature stratification within the droplets.
The performance of the Automated Ice Spectrometer was evaluated using measurements of illite NX, a wellcharacterized test dust that has been used to intercompare 17 immersion mode INP measurement techniques. Four different dilutions of illite NX suspension were measured: $4.0 \times 10^{-3}, 5.0 \times 10^{-3}, 5.0 \times 10^{-2}$, and $6.0 \times 10^{-6} \mathrm{wt} \%$. These concentrations fall in the middle to the lower end of the range of suspension concentrations $\left(3.0 \times 10^{-6}\right.$ to $\left.1.0 \mathrm{wt} \%\right)$ measured by the six selected droplet assay INP measurement techniques in Hiranuma et al. (2015) (see Fig. 9). Measurements of specific site density compare well with the six droplet assay techniques from the intercomparison study (Hiranuma et al., 2015), falling on the warmer side of the $5^{\circ} \mathrm{C}$ spread in the reported spectra from -10 to $-25^{\circ} \mathrm{C}$.

In summary, the Automated Ice Spectrometer

1. enables entirely autonomous measurement of INP concentrations;

2. can measure concentrations of INPs with activation temperatures in the range 0 to $-25^{\circ} \mathrm{C}$;

3. can process up to seven samples per hour using 24 wells per sample (including time for loading samples); 
4. has characterized heat transfer properties so that stratification, temperature offsets from well to well, and offsets between temperature probes and the sample volume can be studied.

Data availability. Data collected for the AIS heat transfer simulations, results, and intercomparison using illite NX are available on https://doi.org/10.6075/J0ZC80S8.

\section{The Supplement related to this article is available online at https://doi.org/10.5194/amt-10-2613-2017-supplement.}

Competing interests. The authors declare that they have no conflict of interest.

Acknowledgements. We would like to thank Joe Mayer for his invaluable help in constructing the AIS housing and camera mount. Funding to support this research was provided by the Center for Aerosol Impacts on Climate and Environment (CAICE), an National Science Foundation (NSF) Center for Chemical Innovation (CHE-1305427).

Edited by: Joachim Curtius

Reviewed by: two anonymous referees

\section{References}

Baustian, K. J., Wise, M. E., and Tolbert, M. A.: Depositional ice nucleation on solid ammonium sulfate and glutaric acid particles, Atmos. Chem. Phys., 10, 2307-2317, https://doi.org/10.5194/acp-10-2307-2010, 2010.

Benchikh, O., Fournier, D., and Boccara, A. C.: Photothermal measurement of the thermal conductivity of supercooled water, Sci. York, 46, 727-731, 1985.

Biddle, J. W., Holten, V., Sengers, J. V., and Anisimov, M. A.: Thermal conductivity of supercooled water, Phys. Rev. E, 87, 1-7, https://doi.org/10.1103/PhysRevE.87.042302, 2013.

Brunauer, S., Emmett, P. H., and Teller, E.: Adsorption of Gases in Multimolecular Layers, J. Am. Chem. Soc., 60, 309-319, https://doi.org/10.1021/ja01269a023, 1938.

Budke, C. and Koop, T.: BINARY: an optical freezing array for assessing temperature and time dependence of heterogeneous ice nucleation, Atmos. Meas. Tech., 8, 689-703, https://doi.org/10.5194/amt-8-689-2015, 2015.

Burrows, S. M., Hoose, C., Pöschl, U., and Lawrence, M. G.: Ice nuclei in marine air: biogenic particles or dust?, Atmos. Chem. Phys., 13, 245-267, https://doi.org/10.5194/acp-13-2452013, 2013.

Churchill, S. and Chu, H.: Correlating equations for laminar and turbulent free convection from a vertical plate, Int. J. Heat Mass Tran., 18, 1323-1329, https://doi.org/10.1016/00179310(75)90222-7, 1975.
Cziczo, D. J., Froyd, K. D., Hoose, C., Jensen, E. J., Diao, M., Zondlo, M. A., Smith, J. B., Twohy, C. H., and Murphy, D. M.: Clarifying the Dominant Sources and Mechanisms of Cirrus Cloud Formation, Science, 340, 1-8, https://doi.org/10.1126/science.1234145, 2013.

Davis, J. R. (Ed.): Metals Handbook, 2nd Edn., ASM International, Materials Park, Ohio, USA, 1521 pp., 1998.

Dehaoui, A., Issenmann, B., and Caupin, F.: Viscosity of deeply supercooled water and its coupling to molecular diffusion, P. Natl. Acad. Sci. USA, 112, 12020-12025, https://doi.org/10.1073/pnas.1508996112, 2015.

DeMott, P. J., Cziczo, D. J., Prenni, A. J., Murphy, D. M., Kreidenweis, S. M., Thomson, D. S., Borys, R., and Rogers, D. C.: Measurements of the concentration and composition of nuclei for cirrus formation, P. Natl. Acad. Sci. USA, 100, 14655-14660, https://doi.org/10.1073/pnas.2532677100, 2003.

DeMott, P. J., Prenni, A. J., Liu, X., Kreidenweis, S. M., Petters, M. D., Twohy, C. H., Richardson, M. S., Eidhammer, T., and Rogers, D. C.: Predicting global atmospheric ice nuclei distributions and their impacts on climate, P. Natl. Acad. Sci. USA, 107, 1121711222, https://doi.org/10.1073/pnas.0910818107, 2010.

DeMott, P. J., Hill, T. C. J., McCluskey, C. S., Prather, K. A., Collins, D. B., Sullivan, R. C., Ruppel, M. J., Mason, R. H., Irish, V. E., Lee, T., Hwang, C. Y., Rhee, T. S., Snider, J. R., McMeeking, G. R., Dhaniyala, S., Lewis, E. R., Wentzell, J. J. B., Abbatt, J., Lee, C., Sultana, C. M., Ault, A. P., Axson, J. L., Diaz Martinez, M., Venero, I., Santos-Figueroa, G., Stokes, M. D., Deane, G. B., Mayol-Bracero, O. L., Grassian, V. H., Bertram, T. H., Bertram, A. K., Moffett, B. F., and Franc, G. D.: Sea spray aerosol as a unique source of ice nucleating particles, P. Natl. Acad. Sci. USA, 113, 5797-5803, https://doi.org/10.1073/pnas.1514034112, 2016.

Hill, T. C. J., Moffet, B. F., DeMott, P. J., Georgakopoulos, D. G., Stump, W. L., and Franc, G. D.: Measurement of ice nucleation-active bacteria on plants and in precipitation by quantitative PCR, Appl. Environ. Microbiol., 80, 1256-1267, https://doi.org/10.1128/AEM.02967-13, 2014.

Hiranuma, N., Hoffmann, N., Kiselev, A., Dreyer, A., Zhang, K., Kulkarni, G., Koop, T., and Möhler, O.: Influence of surface morphology on the immersion mode ice nucleation efficiency of hematite particles, Atmos. Chem. Phys., 14, 2315-2324, https://doi.org/10.5194/acp-14-2315-2014, 2014.

Hiranuma, N., Augustin-Bauditz, S., Bingemer, H., Budke, C., Curtius, J., Danielczok, A., Diehl, K., Dreischmeier, K., Ebert, M., Frank, F., Hoffmann, N., Kandler, K., Kiselev, A., Koop, T., Leisner, T., Möhler, O., Nillius, B., Peckhaus, A., Rose, D., Weinbruch, S., Wex, H., Boose, Y., DeMott, P. J., Hader, J. D., Hill, T. C. J., Kanji, Z. A., Kulkarni, G., Levin, E. J. T., McCluskey, C. S., Murakami, M., Murray, B. J., Niedermeier, D., Petters, M. D., O'Sullivan, D., Saito, A., Schill, G. P., Tajiri, T., Tolbert, M. A., Welti, A., Whale, T. F., Wright, T. P., and Yamashita, K.: A comprehensive laboratory study on the immersion freezing behavior of illite NX particles: a comparison of 17 ice nucleation measurement techniques, Atmos. Chem. Phys., 15, 2489-2518, https://doi.org/10.5194/acp-15-2489-2015, 2015.

Holman, J. P.: Heat transfer, McGraw-Hill series in mechanical engineering, 10, McGraw-Hill Education, 2009.

Hoose, C., Kristjánsson, J. E., Chen, J.-P., and Hazra, A.: A Classical-Theory-Based Parameterization of Heterogeneous Ice 
Nucleation by Mineral Dust, Soot, and Biological Particles in a Global Climate Model, J. Atmos. Sci., 67, 2483-2503, https://doi.org/10.1175/2010JAS3425.1, 2010.

Kell, G. S.: Density, Thermal Expansivity, and Compressibility of Liquid Water from 0 " to $150^{\circ} \mathrm{C}$ : Correlations and Tables for Atmospheric Pressure and Saturation Reviewed and Expressed on 1968 Temperature Scale, J. Chem. Eng. Data, 20, 97-105, https://doi.org/10.1021/je60064a005, 1975.

Klein, H., Haunold, W., Bundke, U., Nillius, B., Wetter, T., Schallenberg, S., and Bingemer, H.: A new method for sampling of atmospheric ice nuclei with subsequent analysis in a static diffusion chamber, Atmos. Res., 96, 218-224, https://doi.org/10.1016/j.atmosres.2009.08.002, 2010.

Mason, R. H., Chou, C., McCluskey, C. S., Levin, E. J. T., Schiller, C. L., Hill, T. C. J., Huffman, J. A., DeMott, P. J., and Bertram, A. K.: The micro-orifice uniform deposit impactordroplet freezing technique (MOUDI-DFT) for measuring concentrations of ice nucleating particles as a function of size: improvements and initial validation, Atmos. Meas. Tech., 8, 24492462, https://doi.org/10.5194/amt-8-2449-2015, 2015.

Phillips, V. T. J., Choularton, T. W., Illingworth, A. J., Hogan, R. J. and Field, P. R.: Simulations of the glaciation of a frontal mixed-phase cloud with the Explicit Microphysics Model, Q. J. Roy. Meteor. Soc., 129, 1351-1371, https://doi.org/10.1256/qj.02.100, 2003.

Rogers, D. C., DeMott, P. J., Kreidenweis, S. M., and Chen, Y.: Measurements of ice nucleating aerosols during SUCCESS, Geophys. Res. Lett., 25, 1383-1386, https://doi.org/10.1029/97GL03779, 1998.

Seinfeld, J. H., Bretherton, C., Carslaw, K. S., Coe, H., DeMott, P. J., Dunlea, E. J., Feingold, G., Ghan, S., Guenther, A. B., Kahn, R., Kraucunas, I., Kreidenweis, S. M., Molina, M. J., Nenes, A., Penner, J. E., Prather, K. A., Ramanathan, V., Ramaswamy, V., Rasch, P. J., Ravishankara, A. R., Rosenfeld, D., Stephens, G., and Wood, R.: Improving our fundamental understanding of the role of aerosol-cloud interactions in the climate system, P. Natl. Acad. Sci. USA, 113, 5781-5790, https://doi.org/10.1073/pnas.1514043113, 2016.
Stopelli, E., Conen, F., Zimmermann, L., Alewell, C., and Morris, C. E.: Freezing nucleation apparatus puts new slant on study of biological ice nucleators in precipitation, Atmos. Meas. Tech., 7, 129-134, https://doi.org/10.5194/amt-7-129-2014, 2014.

Tobo, Y.: An improved approach for measuring immersion freezing in large droplets over a wide temperature range, Sci. Rep., 6, 32930, https://doi.org/10.1038/srep32930, 2016.

Trenberth, K. E. and Fasullo, J. T.: Simulation of present-day and twenty-first-century energy budgets of the southern oceans, J. Climate, 23, 440-454, https://doi.org/10.1175/2009JCLI3152.1, 2010.

Vali, G.: Quantitative Evaluation of Experimental Results an the Heterogeneous Freezing Nucleation of Supercooled Liquids, J. Atmos. Sci., 28, 402-409, https://doi.org/10.1175/15200469(1971)028<0402:QEOERA >2.0.CO;2, 1971.

Vali, G.: Interpretation of freezing nucleation experiments: singular and stochastic; sites and surfaces, Atmos. Chem. Phys., 14, 5271-5294, https://doi.org/10.5194/acp-14-5271-2014, 2014.

VDI-Gesellschaft Energietechnik (Eds.): Engineering reference book on energy and heat, Springer Science, and Business Media, Düsseldorf, 2013.

Whale, T. F., Murray, B. J., O'Sullivan, D., Wilson, T. W., Umo, N. S., Baustian, K. J., Atkinson, J. D., Workneh, D. A., and Morris, G. J.: A technique for quantifying heterogeneous ice nucleation in microlitre supercooled water droplets, Atmos. Meas. Tech., 8, 2437-2447, https://doi.org/10.5194/amt-8-2437-2015, 2015.

Wise, M. E., Baustian, K. J., and Tolbert, M. A.: Internally mixed sulfate and organic particles as potential ice nuclei in the tropical tropopause region, P. Natl. Acad. Sci. USA, 107, 6693-6698, https://doi.org/10.1073/pnas.0913018107, 2010.

Wright, T. P., Petters, M. D., Hader, J. D., Morton, T., and Holder, A. L.: Minimal cooling rate dependence of ice nuclei activity in the immersion mode, J. Geophys. Res.-Atmos., 118, 10535-10543, https://doi.org/10.1002/jgrd.50810, 2013.

Yousef, W. W., Tarasuk, J. D., and McKeen, W. J.: Free Convection Heat Transfer From Upward-Facing Isothermal Horizontal Surfaces, J. Heat Transf., 104, 493, https://doi.org/10.1115/1.3245120, 1982. 